THE RELATIONSHIP BETWEEN

HISTORY AND ARCHITECTURE

THROUGH HENRI BERGSON

KEYWORDS

Time; duration; architecture

ABSTRACT

This work inquires into the texts of Henri Bergson that have delved into the notion of time and reality in order to extract, from their hermeneutics, the present work presuppositions that allow an approach to the history of architecture that is something other than mere memory or description of past events. The notion of duration, inaugurated by the philosopher, opens an irreconcilable gap between history as a catalog of forms and solutions of the past and history as a living tension between those who were and the today, a tension always renewed in each present that is recognized in the generations gone, in Benjamin's words. 


\title{
LA RELACIÓN ENTRE HISTORIA Y ARQUITECTURA A TRAUÉS DE HENRI BERGSON
}

\author{
LANCELle, Anna I.; FERnÁNDEZ, Sergio A.
}

annalancelle@yahoo.com.a

Prof. titular en Historia y Crítica l y Prof. adjunta a cargo en Historia y Crítica II. Profesor responsable Morfología 3. Centro de Estudios Históricos, Arquitectónicos y Urbanos (CEHAU). Facultad de Arquitectura y Urbanismo, UNNE.

PALABRAS CLAUE

Tiempo; duración; arquitectura.

RESUMEN

El presente trabajo indaga en los textos de Henri Bergson que han profundizado sobre la noción de tiempo y de realidad para llegar a extraer, a partir de su hermenéutica, los presupuestos que permitan un acercamiento a la historia de la arquitectura que sea otra cosa que mero recuerdo o descripción de hechos pasados.

La noción de duración, inaugurada por el filósofo, abre una brecha irreconciliable entre la historia como catálogo de formas y soluciones del pasado y la historia como tensión viva entre los que fueron y el hoy, tensión siempre renovada en cada presente que se reconoce en las generaciones idas, en palabras de Benjamin. 


\section{OBJETIUO GENERAL}

Comprender cómo la noción de duración permite entender la historia como instrumento para la proyectación arquitectónica.

\section{OBJETIUOS INSTRUMENTALES}

- Releer los textos de Henri Bergson en los que el autor se ha referido explícitamente a la noción de tiempo y duración.

- Comprender las implicancias de esta noción para el entendimiento de la historia.

- Extraer de esta comprensión de la historia los mecanismos necesarios para instrumentar en la proyectación arquitectónica.

\section{INTRODUCCIÓN}

\section{Algunos antecedentes de la historia de la arquitectura}

La arquitectura se ha nutrido desde siempre de la historia. Esta es una afirmación consensuada tradicionalmente. Ella ha formado parte de la formación, formal o informal, de los arquitectos desde la constitución incipiente de su hacer como oficio y luego su institución como profesión.

De la mano del lluminismo y la Enciclopedia, Jean Louis Durand traerá su famoso "Précis des leçons d'architecture données à l'ecole polythechnique", completo método de proyectación en arquitectura, llamado también "de composición", consistente en un catálogo de motivos históricos (plantas y alzados) que, según su criterio, el diseñador debía elegir y componer.

Para fines del siglo XVIII lo que era un hacer único diverge en la École de Beaux Arts, por una parte, des- tinada a concebir la arquitectura desde sus aspectos más formales que apelaban a rasgos estilísticos tomados de la historia, y la École Nationale des Ponts et Chaussées, por otra, cuyo principal objetivo eran las obras de infraestructura e ingeniería con acento en la faz técnica y que se distanciaba de los ejemplos históricos, aunque sin dejarlos totalmente de lado. El siglo XIX va a ser la apoteosis del Historicismo $y_{\text {, }}$ con él, la de la profundización del método de composición con motivos históricos, por lo que la recurrencia a la historia será condición ineludible para poder hacer arquitectura.

Con el Movimiento Moderno, el siglo $X X$ declara la muerte de la historia. A partir de los postulados de Le Corbusier contra el Eclecticismo, por asociación, la historia pasa a ser denostada por las escuelas y por la propia arquitectura. Desde entonces, la relación historia-arquitectura será una tensión constante, que en la mayoría de los casos no se resuelve apropiadamente. Cuando no se toma la historia como un muestrario de recetas arquitectónicas ya probadas que replicar, se la entiende -en el mejor de los casos - como una sucesión de causas y efectos que permite comprender una arquitectura por su relación con el contexto.

Con el convencimiento de que el aporte de la historia para la arquitectura es mucho más que aquello que se ha mencionado, y que su consideración es fundamental para el hacer arquitectónico, nos hemos acercado a quienes han ido configurando un modo diferente de abordarla. Entre otros, por ejemplo, Friedrich Nietzsche en "De la utilidad y de los inconvenientes de los estudios históricos para la vida" (Nietzsche, 1959) o Walter Benjamin con sus "Tesis de filosofía de la Historia" (Benjamin, 1989). Ambos autores definen lo que entienden por historia. Cada uno a su modo, pretende escapar al sentido de historia lineal y convencional promovido por el Historicismo, pero tristemente vigente aún en nuestro actual modo de entenderla. En la Tesis 5, Benjamin dice:

La verdadera imagen del pasado transcurre rápidamente. Al pasado sólo puede retenérsele en cuanto imagen que relampaguea, para nunca más ser vista, en el instante de su cognoscibilidad. "La verdad no se nos escapará"; esta frase, que procede de Gottfried Keller, designa el lugar preciso en que el materialismo histórico atraviesa la imagen del pasado que amenaza desaparecer con cada presente que no se reconozca mentado en ella. (La buena nueva, que el historiador, anhelante, aporta al pasado viene de una boca que quizás en el mismo instante de abrirse hable al vacío) (Benjamin, 1989, p. 180).

Hemos tomado esta tesis porque es claro que en ella se alude a un modo de comprender el pasado que abole para siempre el sentido lineal, sucesivo y único de lo que se entiende por tiempo, y es aquí donde acudimos a Bergson como autor imprescindible para esclarecer la relación que hoy debería tener la historia con la arquitectura, siendo esto último el objeto de análisis del presente trabajo.

\section{DESARROLLO}

\section{La concepción bergsoniana de la realidad y el tiempo}

En primer término, detengámonos en la noción de realidad dada por Bergson: 
La realidad es crecimiento global e indiviso, invención gradual, duración: como, un globo elástico que se dilata por momentos tomando en todo instante formas inesperadas. Pero nuestra inteligencia se representa el origen y la evolución como un ajuste y reajuste de partes que no harían más que cambiar de lugar; ella podría pues teóricamente prever no importa quéestado de conjunto: poniendo un número definido de elementos estables, se dan implícitamente por anticipado, todas las combinaciones posibles. Esto no es todo. La realidad, tal como la percibimos directamente, es un lleno que no cesa de henchirse, y que ignora elvacío. Tiene extensión como tiene duración; pero esta extensión concreta no es el espacio infinito e infinitamente divisible que la inteligencia se da como un terreno donde construir. El espacio concreto ha sido extraído de las cosas. Ellas no están en él, es él el que está en ellas. Solamente cuando nuestro pensamiento razona sobre la realidad hace del espacio un receptáculo. Como tiene costumbre de reunir partes en un vacío relativo, se imagina que la realidad colma no sé qué vacío absoluto (Bergson, 1976, p. 93).

En efecto, esta apreciación sobre la realidad hecha por el filósofo ha sido corroborada luego por la física cuántica. La realidad no es una sola, objetiva, allá afuera; la realidad se constituye en el instante en que la percibimos. Experiencias como la denominada "de la doble rendija" (figura 1) permiten comprender que mientras no la percibimos, lo que denominamos realidad es un todo indiviso, flujo de ondas en constante movimiento, mientras que cuando anclamos nuestra atención en ella, lo que percibimos es una sucesión de partículas.
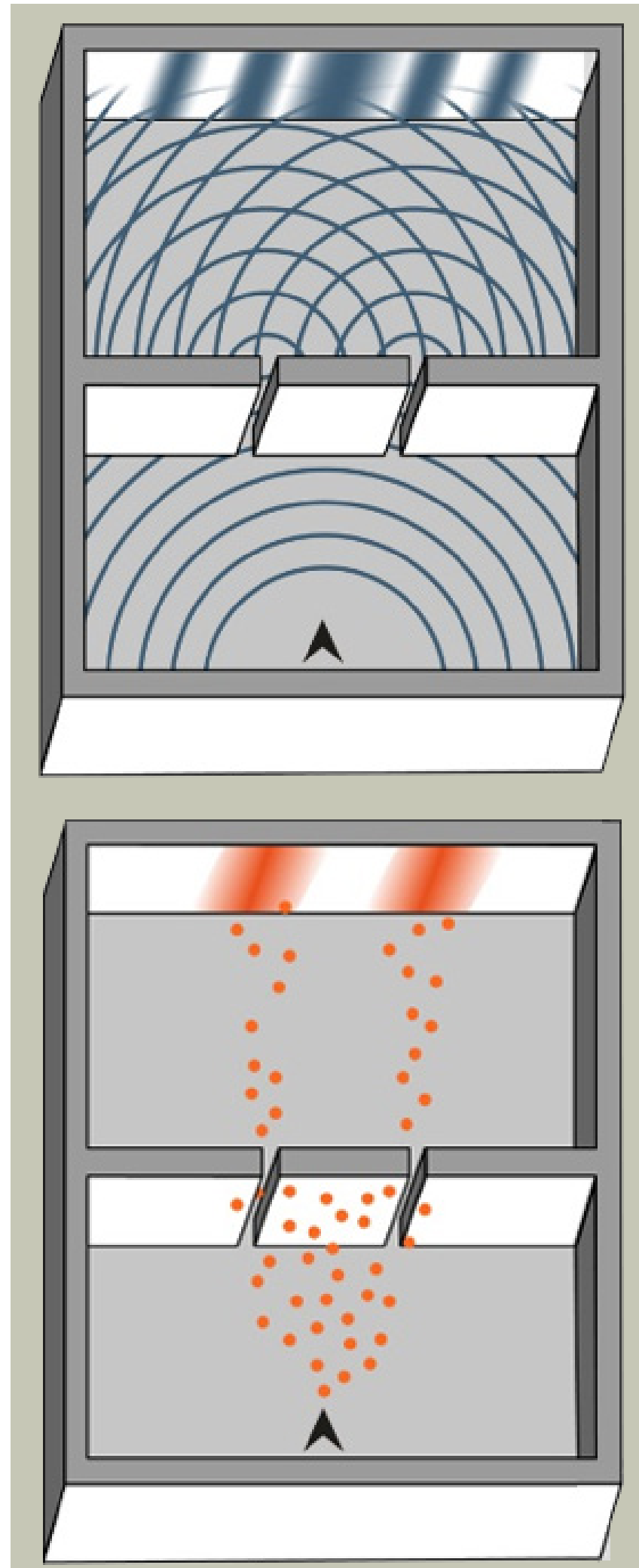

Figura 1. Comparación entre el comportamiento de ondas y partículas. Fuente: https://blogs.20minutos.es/ciencia-para-llevar-csic/2015/11/12/el-experimento-fisico-mas-hermoso-de-todos-de-los-tiempos-la-doble-rendija/ 
La figura 1 corresponde a la propagación en ondas de un electrón y la de la derecha, a la de partículas, en este caso canicas. Al colocar un detector para averiguar por qué rendija pasa el electrón que debería propagarse como onda, el "patrón de interferencia" desaparece y los electrones impactan en la segunda placa como si fuesen canicas. Es decir que, al tratar de observar el sistema, se ha actuado sobre él obligando al electrón a comportarse como una partícula. Los fotones que hemos enviado para detectarlo han interaccionado con él y alterado el resultado del experimento.

Al decir de Bergson, a esta especie de ilusión debemos el hecho de que entendamos que lo posible es menos que lo real y que por ello la posibilidad de las cosas precede a su existencia. Por ello mismo, creemos que las cosas podrían representarse de antemano, es decir, podrían ser pensadas antes de ser realizadas, 0 lo que es lo mismo, lo posible estaría allí esperando y puede ser real por algo que se le vendría a añadir.

Esta operación de nuestro intelecto se da en definitiva en el tiempo, y, según Bergson, si un acontecimiento (realidad) se explica por tales o cuales antecedentes (posibles), es en verdad porque estos están recortados de entre tantos otros antecedentes por una atención retrospectiva que los elige en función del acontecimiento. Esto es que, contrariamente a lo que nuestros hábitos mentales nos hacen percibir, el pasado se modela por el presente, la causa por el efecto. "Por eso es necesario tomar partido: es lo real lo que se hace posible, y no lo posible lo que llega a ser real" (Bergson, 1976, p. 99).

Esta misma lógica puede aplicarse a la noción de tiempo.
Lo que quiero sobre todo decir es que está astricto el conocimiento usual, como el conocimiento científico y por las mismas razones que él, a tomar las cosas en un tiempo pulverizado, donde un instante sin duración sucede a otro instante que no dura más. El movimiento es una serie de posiciones, el cambio una serie de cualidades, el llegar a ser, una serie de estados. Parte de la inmovilidad (como si la inmovilidad pudiera ser otra cosa que una apariencia, comparable al efecto especial que un móvil produce sobre otro móvil cuando están regulados uno sobre otro), y por un ingenioso ordenamiento de inmovilidades recompone una imitación del movimiento que sustituye al movimiento mismo (Bergson, 1976, p. 118).

Pero el tiempo y el cambio que habitualmentepresenciamossonuntiempo y un cambio reducidos, recortados. Así, nos figuramos el movimiento como una sucesión de estados de un móvil en el espacio, ya que nuestros hábitos mentales, acostumbrados a las fijezas, así lo requieren para facilitar nuestra acción sobre las cosas. Pero si olvidamos esta necesidad de actuar, aparecerá el solo movimiento, la duración, es decir un presente que dura. Para ello, Bergson dirá:

Recuperémonos por el contrario, tal como somos, en un presente espeso y además elástico, que podemos dilatarindefinidamente hacia atrás, haciendo retroceder cada vez más lejos la pantalla que nos enmascara a nosotros mismos; recuperemos el mundo exterior tal comoes, no solamente la superficie en el momento actual, sino la profundidad, con el pasado inmediato que le oprime y que le imprime su impulso; habituémonos en una palabra, a ver todas las cosas sub specie durations: al momento se afloja lo que está tenso, se despierta lo que está dormido, resucita lo que está muerto en nuestra percepción galvanizada(Bergson, 1976, p. 120)

Para que esto sea, es necesario que la atención a la vida se distienda. En la experiencia de las dos rendijas, si dejamos de enfocar nuestra atención hacia ellas, la realidad como sucesión de partículas deja de existir y se transforma en un movimiento de ondas o flujo. Asimismo, si prestamos nuestra atención a un interés en particular, el movimiento se particiona en presente (lo que es de nuestro interés actual) y pasado (aquello a lo que dejamos de prestarle atención), por lo que percibimos el tiempo como sucesión. Sin embargo, si la atención se desliga de todo interés práctico, toda la vida se transforma en continuamente presente. Un presente indiviso, un presente que dura, duración.

Ahora bien, estos modos de acercarnos a la realidad y el tiempo implican dos modos de concebir radicalmente diferentes, lo que permite distinguir a la vez dos maneras de conocer.

La primera implica que se gira en torno a esta cosa; la segunda que se entra en ella. La primera depende del punto de vista del que la mira y de los símbolos por los que se expresa. La segunda no depende de ningún punto de vista y no se apoya sobre ningún símbolo. Del primer conocimiento se dirá que se atiene a lo relativo; del segundo, dentro de lo posible, que alcanza lo absoluto (Bergson, 1976, pp. 147-148).

Es así que el conocimiento relativo nos deja fuera de la cosa, y todo lo que podemos hacer es analizarla o describirla, pero, aunque se multipliquen infinitamente nuestros análisis 
y miradas, jamás tendremos la noción exacta de la cosa. El conocimiento absoluto, en cambio, nos instala en la cosa misma, simpatizamos con ella de manera que coincidimos con lo que tiene de único e inefable.

En el análisis, intentamos llegar al conocimiento de la cosa sirviéndonos de otros objetos conocidos que no son la cosa misma, mientras que en el esfuerzo de simpatizar con la cosa, al que llamaremos intuición, la captamos desde su interior en un acto simple.

\section{Nuestro objeto de estudio a la luz de la realidad y el tiempo bergsonianos}

Si intentamos observar a partir de los fragmentos anteriores nuestro objeto de análisis, es decir, la historia de la arquitectura y la relación que existe entre historia y arquitectura, deberíamos rever en primer lugar el concepto de historia.

De unas nociones de realidad y tiempo como las expresadas en el inicio, se desprende un concepto de historia que le corresponde. La historia no es "una", objetiva, allá afuera; la historia es un cúmulo de interpretaciones. La nuestra no debería ser una más. No, si entendemos por interpretación una reconstrucción de jirones de tiempo que pueden ser hilados como las perlas de un collar. Tal como lo expresa Bergson para los acontecimientos en general, deberíamos asimilarlo para la historia en particular. Se trata de que el pasado se modele en función del presente, esto es, de modelar el pasado en función de los requerimientos actuales. Pero para poder hacerlo es necesario operar con un conocimiento de tipo absoluto, coincidiendo con la cosa, es decir, con la historia, por un esfuerzo de intuición, de modo que nuestra actualidad coincida con lo pasado. ¿Cómohacerlo? Trayendo la historia de la arquitectura al presente. Volviendo a ver a los romanos, a los griegos, a los mayas construyendo y tomando de ello lo necesario para nuestro hacer actual.

Tal como en el ejemplo citado por Bergson de las veinte estaciones de radio que emiten veinte conciertos diferentes, en que cada receptor sintonizará aquella emisora que tenga la misma longitud de onda, según nuestras necesidades tomaremos de la historia aquello que nos sea afín. Esto permitirá la creación de una historia siempre nueva, en la cual es cada presente el que exige reconocerse en el pasado.

Así, la frase de Benjamin adquiere un nuevo sentido, más ajustado a sus posibilidades concretas y prácticas Volvamos a ella:

La verdadera imagen del pasado transcurre rápidamente. Al pasado sólo puede retenérsele en cuanto imagen que relampaguea, para nunca más ser vista, en el instante de su cognoscibilidad. "La verdad no se nos escapará"; esta frase, que procede de Gottfried Keller, designa el lugar preciso en que el materialismo histórico atraviesa la imagen del pasado que amenaza desaparecer con cada presente que no se reconozca mentado en ella. (La buena nueva, que el historiador, anhelante, aporta al pasado viene de una boca que quizás en el mismo instante de abrirse hable al vacío).

Así, la imagen del pasado como única verdad que es posible asir de una vez y para siempre se desvanece ante la concepción de una historia que permite a cada presente reconocerse en ella. Que cada presente se reconozca en la historia significa, a su vez, que la memoria se actualice en el presente, y esto solo se realiza en función de una necesidad actual, siempre nueva y distinta. Cuando el pasado se extiende al presente, aquel se modifica con este, y da así una continuidad siempre móvil.

\footnotetext{
Tomemos el más estable de los estados internos: la percepción visual de un objeto exterior inmóvil. Por más que el objeto sea el mismo, por más que lo mire desde el mismo lado, bajo el mismo ángulo y en el mismo día, la visión que tengo no difiere menos de la que acabo de tener, aunque sólo sea porque esa visión ha envejecido un instante. Mi memoria interviene y extiende algo de ese pasado al presente. Mi estado de espíritu, al avanzar por el camino del tiempo, se acrece continuamente con la duración que recoge; hace, por decirlo así, la bola de nieve consigo mismo. Con tanta más razón sucede eso mismo con los estados más profundamente interiores, sensaciones, sentimientos, deseos, etc., que no corresponden, como la simple percepción visual, a un objeto exterior invariable(Bergson, 1985, pp. 15-16).
}

Es cierto que nuestra intelección comprende más fácilmente el "logos" en su doble significación, como lógica y como lenguaje. Por lo tanto, cualquier proceso vital se traduce en nuestro entendimiento como una sucesión de etapas espacializadas, distintas y separadas. Esto es, según el propio filósofo, una imitación artificial de la vida interior, que se prestará mejor a las exigencias de la lógica y del lenguaje, pero en la que se habrá eliminado el tiempo real.

Pues nuestra duración no consiste en un instante que reemplaza a otro instante; sólo habría entonces presente, y no una prolongación del pasado en lo actual, una evo- 
lución, una duración concreta. La duración es el continuo progreso del pasado que va comiéndose al futuro y va hinchándose al progresar (Bergson, 1985, p. 18).

Nuestro pasado permanece presente en nosotros, somos una condensación de la historia que hemos vivido, aunque solo una parte de él llegue a expresarse.

De esa supervivencia del pasado se deriva la imposibilidad, para la conciencia, de atravesar dos veces el mismo estado. Por más que las circunstancias sean las mismas, ya no actúan estas sobre la misma persona, pues la encuentran en un nuevo momento de su historia. Nuestra personalidad que se debate en cada instante con la experiencia acumulada, cambia sin cesar. Al cambiar impide que un estado, aunque superficialmente sea idéntico a sí mismo, se repita en su fondo. Por ello es irreversible nuestra duración (Bergson, 1985, p. 19).

Esta irreversibilidad hace que la duración sea esencialmente productora de algo nuevo, y aquí la tesis de Bergson adquiere una relevancia inusitada para la arquitectura.

El retrato acabado se explica por la fisonomía del modelo, por la naturaleza del artista, por los colores desleídos en la paleta; pero incluso conociendo lo que lo explica, nadie, ni siquiera el artista, habría podido prever exactamente lo que sería el retrato, pues predecirlo equivaldría a producirlo antes de que fuese producido, hipótesis absurda que se destruye a sí misma. Y lo mismo sucede con los momentos de nuestra vida, de los cuales somos artífices. Cada uno de ellos es una especie de creación (Bergson, 1985, pp. 19-20).

Es así que comprender la memoria y el tiempo de este modo es entenderlos como posibilidad siempre renovada de creación. "El Universo dura. Cuanto más profundicemos en la naturaleza del tiempo, mejor comprenderemos que duración significa invención, creación de formas, elaboración continua de lo absolutamente nuevo" (Bergson, 1985, p. 23).

Ahora bien, para nuestro entendimiento, es tarea cómoda y accesible representarse cualquier proceso vital en el tiempo como si se tratase de espacio; es así que lo que denominamos inteligencia fija cada momento del tiempo en un punto del espacio, por lo que cualquier movimiento puede ser descompuesto por una serie de detenciones en él. Por lo antes dicho la suma de estas detenciones jamás recompondrá el tiempo vital real. Todas las instantáneas que tomemos de un movimiento no reemplazarán el movimiento en sí.

Del mismo modo que separamos en el espacio, fijamos en el tiempo. La inteligencia no está hecha para pensar la evolución, en el sentido propio de la palabra, es decir, la continuidad de un cambio que sería pura movilidad. No insistiremos aquí sobre ese punto que nos proponemos profundizar en un capítulo especial. Digamos tan sólo que la inteligencia se representa el devenir como una serie de estados, cada uno de los cuales es homogéneo consigo mismo y, por consiguiente, no cambia (Bergson, 1985, p. 150)

Es la inteligencia la que, por su mecanismo de aprehensión, recorta el movimiento y recorta el devenir en paradas sucesivas, inventando para nuestra comodidad los artificios de la sucesión en el espacio y en el tiempo.

\section{La inteligencia, el instinto y la intuición}

En la medida en que operen la inteligencia y sus hábitos, solo se llegará a la reconstrucción por recomposición de instantes del movimiento, sin llegar al movimiento mismo.

También aquí pensar consiste en reconstruir $y$, naturalmente, reconstruimos con elementos dados, por consiguiente, estables. De modo que por más que hagamos, podremos imitar, eso sí, la movilidad del devenir, mediante el progreso indefinido de nuestra adición, pero el devenir mismo se nos escapará entre los dedos cuando creamos tenerlo ya (Bergson, 1985, p. 151).

Por ello, Bergson puede referirse a la inteligencia diciendo que se caracteriza por una natural incomprensión de la vida. Pero si no conocemos por la inteligencia, ¿cómo conocemos? Es sabido que, en otro extremo de la naturaleza humana, se encuentra su animalidad. ¿Podría ser, entonces, el instinto un mejor y más natural modo de conocer? ¿Podría el instinto acercarnos a conocer el tiempo, la realidad y sus procesos vitales?

Ahora bien, el instinto es también un conocimiento a distancia. Es a la inteligencia lo que la visión es al tacto. La ciencia no podrá hacer más que traducirlo en términos de inteligencia, pero así construirá una imitación del instinto antes que penetrar en el instinto mismo (Bergson, 1985, p. 155)

Por lo tanto, instinto e inteligencia, siendo diametralmente opuestos, no pueden, sin embargo, introducirnos en el conocimiento profundo de lo vivo.

El instinto es simpatía. Si dicha simpatía pudiera extender su objeto y reflexionar también sobre sí misma, nos daría la clave de las operaciones vitales -lo mismo que la inteligencia, desarrollada y corregida, nos introduce de lleno en la materia-. Pues nunca lo repetiremos bastante, la inteligencia y el instinto están dirigido en dos sentidos opuestos; aquella, hacia la materia inerte; éste, hacia la vida. La inteligencia, por mediación de la ciencia, que es su obra nos entregará, de un modo cada vez más completo, el secreto de las operaciones físicas; de la vida sólo nos da una traducción en términos de inercia, ni tampoco pretende 
darnos más. Gira en torno suyo, tomando, desde fuera el mayor número posible de puntos de vista sobre ese objeto que atrae hacia ella, en lugar de entrar en él. Mas al interior mismo de la vida es adonde nos conduciría la intuición, es decir, el instinto que se ha vuelto desinteresado, consciente de sí mismo, capaz de reflexionar sobre su objeto y de ensancharlo indefinidamente (Bergson, 1985, p. 162).

Así, ni la inteligencia ni el instinto pueden conducirnos al conocimiento de la vida; sin embargo, sí podría hacerlo el esfuerzo de intuición, que es un modo consciente del instinto y que permite penetrar en la cosa misma, acceder al conocimiento absoluto.

\section{REFLEXIONES FINALES}

\section{La historia como duración}

Ahora bien, ¿qué utilidad puede tener una historia concebida en términos de duración? O también podríamos preguntar ¿en qué se relaciona una historia concebida de este modo con el hacer arquitectónico?

Siguiendo con el razonamiento del inicio, la historia, en relación con el hacer arquitectónico, forma parte de sus antecedentes; pero como también se ha dicho, estos no lo anteceden, sino que se configuran con él, en la medida en que es el hacer el que busca en la historia y elije lo que ha de presentizar. Lo que es lo mismo que decir que modelamos la historia según nuestra necesidad actual.

Supongamos que el proceso del hacer se nutre de la percepción actual y que la historia es su recuerdo en el sentido de percepciones de arquitecturas pasadas. Bergson dirá: Suponemos que la formación del recuerdo nunca es posterior a la de la percepción; tiene lugar a la vez que ésta. A medida que se crea la percepción, el recuerdo se va perfilando a su lado, como la sombra al lado del cuerpo (Bergson, 1982, p. 137).

A pesar de que nuestra conciencia no lo percibe de este modo. "Lo que en cada instante se desdobla en percepción y recuerdo es la totalidad de lo que vemos, oímos y experimentamos, todo lo que somos con todo lo que nos rodea" (Bergson, 1982, p. 143)

Para completar la explicación de este complejo mecanismo, profundicemos en lo siguiente:

Sufriríamos una curiosa equivocación acerca del mecanismo del reconocimiento si creyéramos que empezamos por ver y oír, y que luego, una vez constituida la percepción, la aproximamos a un recuerdo semejante para reconocerla. Lo cierto es que el recuerdo es lo que nos hace ver y oír, y que la percepción por sí misma sería incapaz de evocar el recuerdo que se le asemeja, puesto que para eso sería necesario que hubiese tomado ya forma y estuviese lo suficientemente completa; pero sólo se convierte en percepción completa y sólo adquiere una forma distinta mediante el recuerdo mismo que se introduce en ella y le proporciona la mayor parte de su materia (Bergson, 1982, p. 175).

Es decir, la percepción actual se completa cuando es el recuerdo, o, en otras palabras: la historia, la que se introduce en ella. Así, la percepción evoca al recuerdo a la vez que el recuerdo le otorga su materia modelándose mutuamente.

\section{El esfuerzo de intuición y la arquitectura}

Lo descripto, que es en definitiva un proceso de conocimiento, requiere un esfuerzo intelectual. Sin embargo, el grado superior de este esfuerzo es el esfuerzo de invención
Uno se representa un ideal, es decir, un determinado efecto obtenido, dice Ribot, y entonces se busca qué composición de elementos producirá ese efecto. De un salto se traslada uno al resultado completo, al fin que se trata de realizar; entonces, todo el esfuerzo de invención es un intento para colmar el intervalo por encima del cual se ha saltado, y llegar de nuevo a ese mismo fin, siguiendo esta vez el hilo continuo de los medios que lo realizarían. Mas ¿cómo percibir aquí el fin sin los medios, el todo sin las partes? No será en forma de imagen, pues una imagen que nos hiciera ver el efecto que está realizándose nos mostraría, dentro de esa imagen misma, los medios por los que el efecto se realiza. Nos es forzoso admitir que el todo se ofrece como un esquema, y que la invención consiste precisamente en convertir el esquema en imagen (Bergson, 1982, p. 178)

Es este esfuerzo de invención la condición para que el proceso creativo en el hacer arquitectónico se complete. Ahora bien, es necesario, para llegar a este esquema primero y para luego convertirlo en imagen un trabajo de inteligencia flexible, o tomando un término utilizado antes, un esfuerzo de intuición.

La imagen de contornos precisos dibuja lo que ha sido. Una inteligencia que sólo operase sobre imágenes de este tipo no podría volver a comenzar su pasado más que como fue, o tomaría sus elementos petrificados para recomponerlos en un orden distinto, merced a un trabajo de mosaico. Mas una inteligencia flexible, capaz de utilizar su experiencia pasada adaptándola a las líneas del presente, necesita, al lado de la imagen, una representación de especie diferente, siempre capaz de realizarse en imágenes, aunque siempre distinta de ellas. No otra cosa es el esquema (Bergson, 1982, p. 189). 
Pero si a la invención hemos de llegar a través de la intuición, debemos conocer cuáles son las condiciones que la ponen en movimiento.

Bergson distinguirá el estado de ensueño del de vigilia, asimilando este último con el estado útil necesario para el operar del intelecto, mientras que el del ensueño es un estado en que la atención a la vida se relaja, en que la tensión se afloja y no hay interés inmediato en una actuar utilitario a la vida, es decir, con una finalidad determinada. Ello propiciará la coincidencia absoluta con la cosa, es decir, la intuición.

[E]l estado de ensueño se nos aparecerá, por el contrario, como el substratum de nuestro estado normal. No se sobreañade al estado de vigilia; es el estado de vigilia el que se obtiene mediante la limitación, la concentración y la tensión de una vida psicológica difusa, que es la vida del ensueño. En cierto sentido, la percepción y la memoria que se ejercitan en el ensueño son más naturales que las del estado de vigilia. En el ensueño la conciencia se divierte en percibir por percibir, en recordar, sin ninguna preocupación por la vida, es decir, por la acción a realizar (Bergson, 1982, p. 135)

Las maneras en que el hacer arquitectónico se ha relacionado con la historia han sido en la mayoría de los casos modos que han ido desde la indiferencia total a otros de tipo extensivo, en los cuales el esfuerzo intelectual se ha concentrado en tomar imágenes del pasado como si se tratase de un reservorio inmóvil con cuyas piezas componer algo que jamás será un todo, sino solamente un conjunto de partes.
A la luz de los textos de Bergson, creemos que este error parte de un modo de concebir la realidad y el tiempo como algo objetivo, fijo e inmóvil, con lo que no podemos interactuar. Esta concepción es la misma que confía ciegamente en el conocimiento que se construye en referencia a parámetros establecidos y consensuados universalmente, en la inteligencia como único modo de conocer y en el trabajo arduo con el único fin de llegar a un resultado previsto como manera de accionar en la realidad. A partir de Bergson, el pasado se modela por el presente, la sucesión se convierte así en duración la que solo podrá ser captada necesariamente por una intuición, nacida del conocimiento absoluto, todo lo cual permite que, de cuando en cuando, se llegue a la creación.

\section{REFERENCIAS BIBLIOGRÉFICAS}

Benjamin, W. (1989). Discursos Interrumpidos I. Taurus.

Bergson, H. (1976). El pensamiento y lo moviente. Espasa Calpe.

Bergson, H. (1982). La energía espiritual. Espasa Calpe.

Bergson, H. (1985). La evolución creadora. Espasa Calpe.

Nietzsche, F. (1959). Consideraciones Intempestivas. Aguilar.

\section{DOCUMENTO EN INTERNET}

Mar Gulis (12 de noviembre de 2015) Ciencia para llevar. El blog del CSIC. https://blogs.20minutos.es/ciencia-para-Ilevar-csic/2015/11/12/ el-experimento-fisico-mas-hermoso-de-todos-de-los-tiempos-la-doble-rendija/ 
